
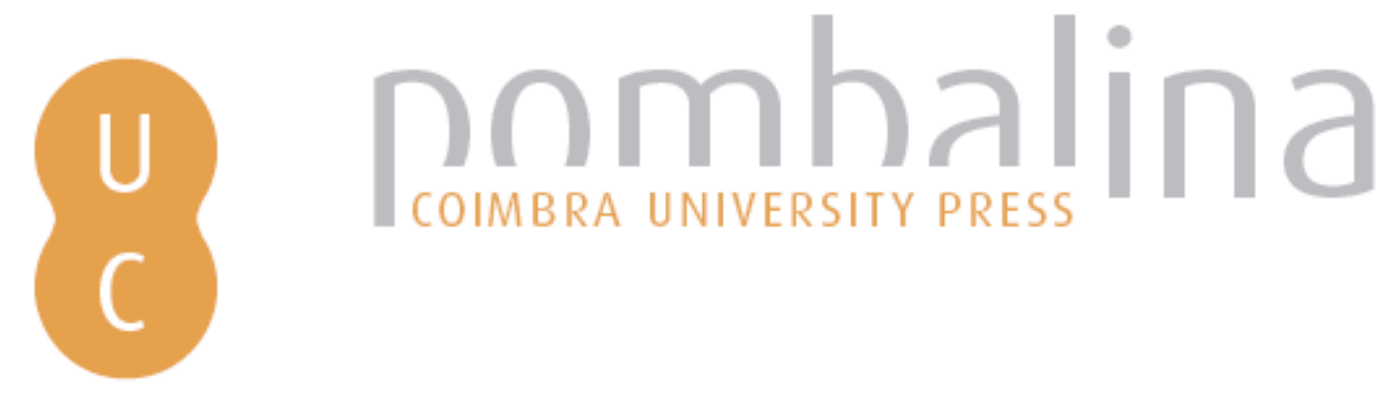

\title{
Predicting wildfire ignitions, escapes, and large fire activity using Predictive Service's 7-Day Fire Potential Outlook in the western USA
}

Autor(es): $\quad$ Riley, Karin L.; Stonesifer, Crystal; Preisler, Preisler; Calkin, Dave

Publicado por: Imprensa da Universidade de Coimbra

URL

persistente:

URI:http://hdl.handle.net/10316.2/34350

DOI:

DOI:http://dx.doi.org/10.14195/978-989-26-0884-6_135

Accessed : $\quad$ 26-Apr-2023 15:06:06

A navegação consulta e descarregamento dos títulos inseridos nas Bibliotecas Digitais UC Digitalis, UC Pombalina e UC Impactum, pressupõem a aceitação plena e sem reservas dos Termos e Condições de Uso destas Bibliotecas Digitais, disponíveis em https://digitalis.uc.pt/pt-pt/termos.

Conforme exposto nos referidos Termos e Condições de Uso, o descarregamento de títulos de acesso restrito requer uma licença válida de autorização devendo o utilizador aceder ao(s) documento(s) a partir de um endereço de IP da instituição detentora da supramencionada licença.

Ao utilizador é apenas permitido o descarregamento para uso pessoal, pelo que o emprego do(s) título(s) descarregado(s) para outro fim, designadamente comercial, carece de autorização do respetivo autor ou editor da obra.

Na medida em que todas as obras da UC Digitalis se encontram protegidas pelo Código do Direito de Autor e Direitos Conexos e demais legislação aplicável, toda a cópia, parcial ou total, deste documento, nos casos em que é legalmente admitida, deverá conter ou fazer-se acompanhar por este aviso.

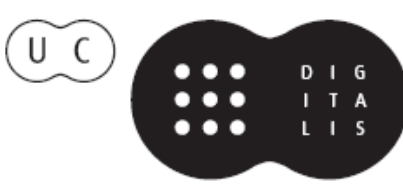




\section{ADVANCES IN}

Forest Fire

\section{RESEARCH}

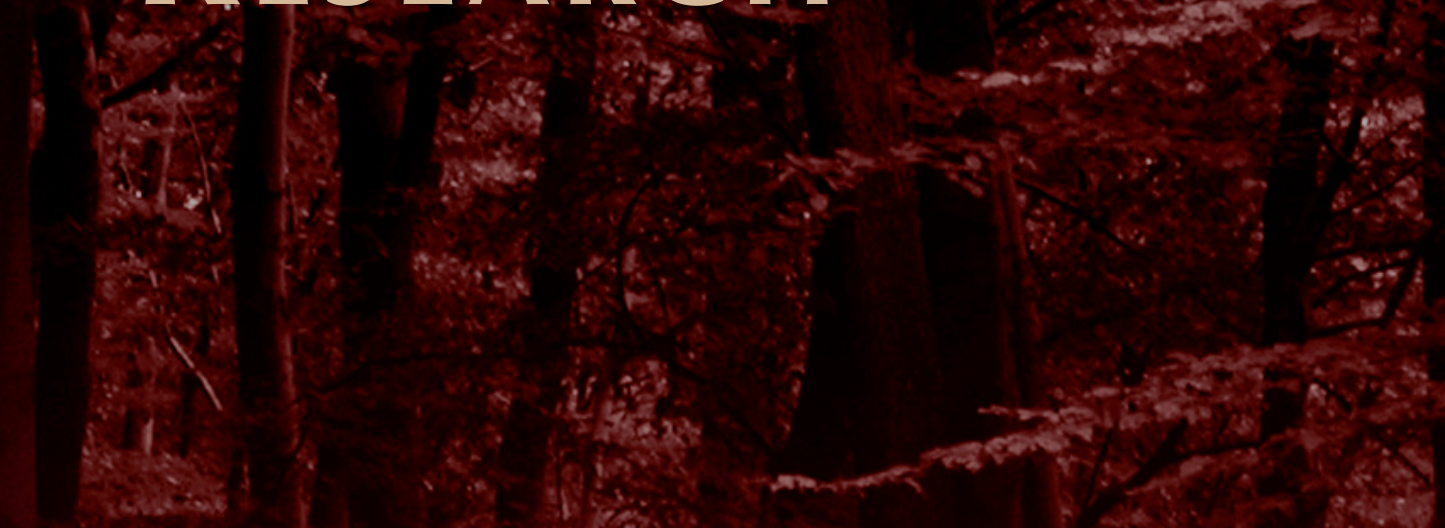

\section{DOMINGOS XAVIER VIEGAS}

\section{EDITOR}




\title{
Predicting wildfire ignitions, escapes, and large fire activity using Predictive Service's 7-Day Fire Potential Outlook in the western USA
}

\author{
Karin L. Riley ${ }^{\mathrm{a}}$, Crystal Stonesifer ${ }^{\mathrm{b}}$, Haiganoush Preisler ${ }^{\mathrm{c}}$, and Dave Calkin ${ }^{\mathrm{d}}$ \\ ${ }^{a}$ College of Forestry and Conservation, University of Montana, 32 Campus Drive, Missoula, \\ Montana, USA, 59812, karin.riley@umontana.edu \\ ${ }^{b}$ Human Dimensions, Rocky Mountain Research Station, 200 East Broadway, Missoula, Montana, \\ USA 59807, csstonesifer@fs.fed.us \\ ${ }^{c}$ Pacific Southwest Research Station, 800 Buchanan St., West Annex Building, Albany, California, \\ USA,94710,hpreisler@fs.fed.us \\ ${ }^{d}$ Human Dimensions, Rocky Mountain Research Station, 200 East Broadway, Missoula, Montana, \\ USA 59807, decalkin@fs.fed.us
}

\begin{abstract}
Can fire potential forecasts assist with pre-positioning of fire suppression resources, which could result in a cost savings to the United States government? Here, we present a preliminary assessment of the 7-Day Fire Potential Outlook forecasts made by the Predictive Services program. We utilized historical fire occurrence data and archived forecasts to assess how well the 7-Day Outlook predicts wildfire ignitions and escaped fires, ultimately to help characterize the effectiveness of this tool for prepositioning national firefighting resources. The historical fire occurrence data track ignitions on all land ownerships; from this dataset, we established number and location of ignitions and final fire size for the years 2009-2011 for Predictive Service Areas (PSAs) within the Northwest and Southwest Geographic Areas. These data were then matched to the corresponding PSA and appropriate forecast for each of the seven days prior to the ignition date. Final fire size was used as a metric to establish whether an ignition escaped initial attack, with fires greater than 121.4 hectares (300 acres) considered escaped. Our results show that 7-Day Outlook values yield better-than-random prediction of large fire activity, although there is wide variation in this relationship among individual PSAs. In addition, the number of escaped fires increased with the number of ignitions, with this relationship showing a distinct regional pattern. Fires were more likely to escape during certain times of the year, with this season being earlier in the Southwest than in the Northwest. Significantly higher numbers of escaped fires per ignition occurred during days considered to be high risk by the meteorologist than on lower-risk days.
\end{abstract}

Keywords: forecasting; fire danger; ignitions; escaped fires; large fire activity

\section{Introduction}

Accurate predictions of days and locations with heightened potential for significant wildfire activity would be valuable for a number of planning functions, including giving land managers time to evaluate potential responses in the event of an ignition, such as prepositioning of fire suppression resources. The 7-Day Fire Potential Outlook forecasts issued by the Predictive Service program in the United States (US) might be suitable for such tasks, but they have not yet been assessed at the necessary national scale. In this manuscript, we present preliminary assessment of this product for two regions of the US.

The Predictive Services program was created under the National Wildfire Coordinating Group in 2001 to address the need for long- and short-term decision support information for fire managers and operations personnel. The primary mission of Predictive Services is to integrate fire weather, fire danger, and resource availability in order to enable strategic fire suppression resource allocation and prioritization. The conterminous United States is divided into ten Geographic Coordination Areas (GCAs; Figure 1), which are in turn comprised of individual forecast units called Predictive Service Areas (PSAs; Figure 2). PSAs are delineated within each GCA to represent geographic areas of similar 
climate based on statistical correlation of observed weather and fuel moisture data, or based on political or land ownership boundaries. In 2006, Predictive Services began daily production of the 7-Day Significant Fire Potential Outlook for each PSA on weekdays during the core fire season to support efforts at informed regional and national fire suppression resource allocation and prepositioning.

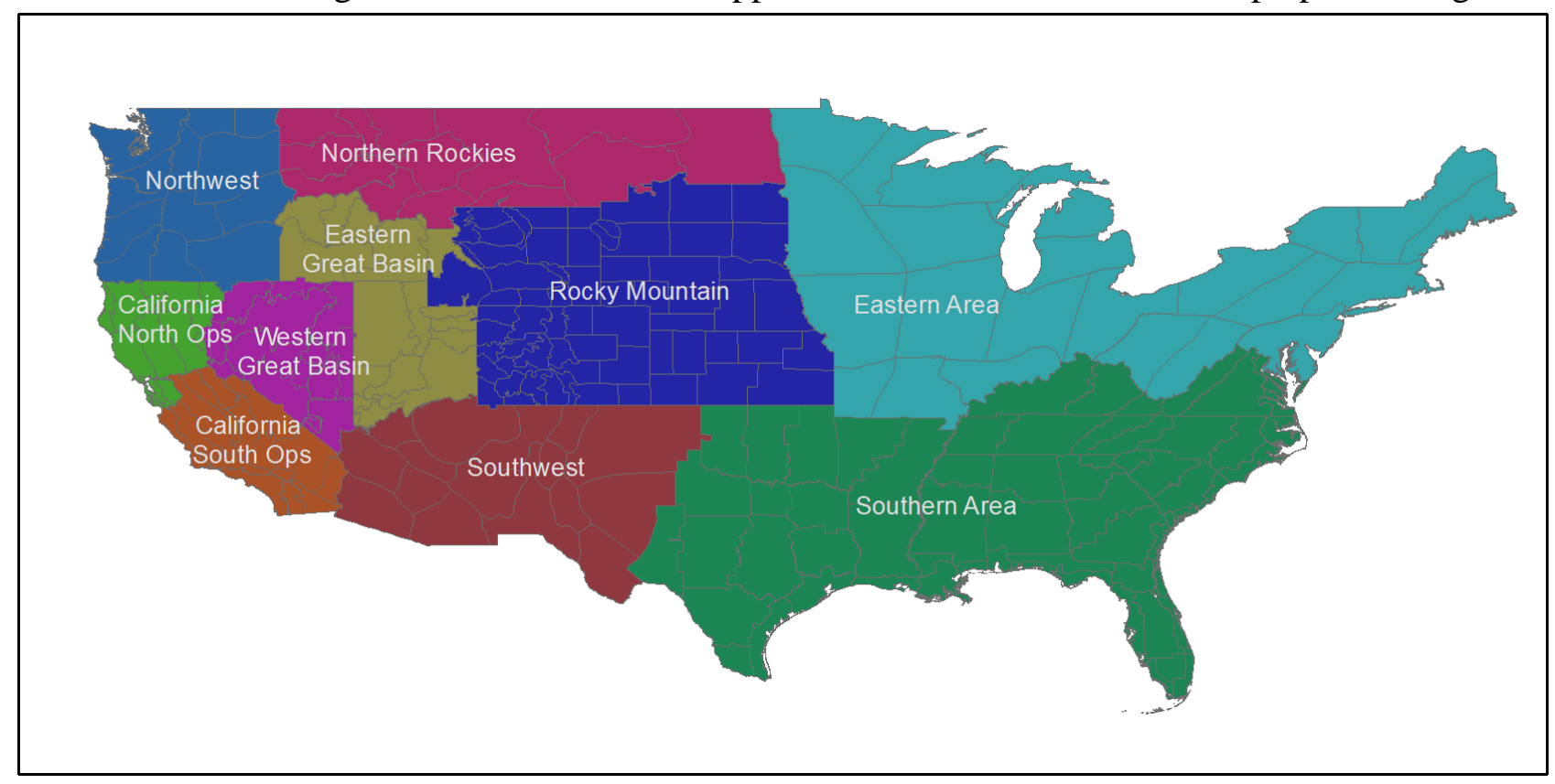

Figure 1. Geographic Coordination Areas (GCAs) of the conterminous US. The boundaries of the Predictive Service Areas (PSAs) for the year 2012 are shown in gray.

The 7-Day Outlook uses forecasted fuel dryness and specific high-risk weather events to predict the location and timing of demand for regionally and nationally shared suppression resources. Thus, it is essentially designed to anticipate significant fire activity. More specifically, Predictive Services defines "Significant Fire Potential" as "the likelihood that a wildland fire event will require mobilization of additional resources from outside the area in which the fire situation occurs" (www.nwccweb.us/content/products/fwx/fdrop/FDROP.pdf, accessed May 9, 2014). "Significant fires" are defined to be those larger than a threshold size, which varies geographically, based on historical fire sizes. 


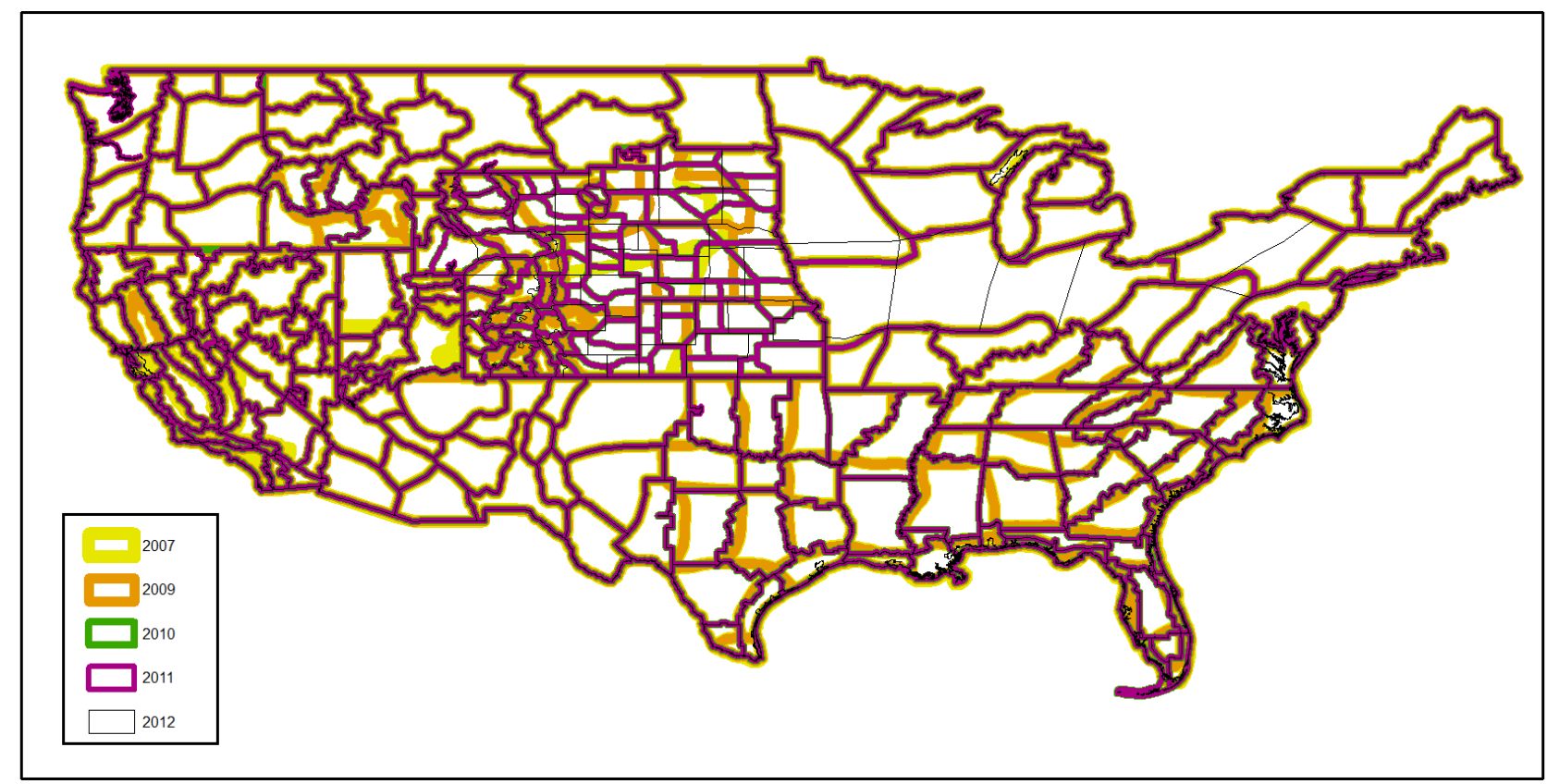

Figure 2. Boundaries of Predictive Service Areas (PSAs) in the conterminous US. Boundaries have changed significantly in some GCAs since their inception in 2006.

The Fire Potential Forecasts are made on a categorical scale of 1 to 9 for the current day and each of the following six days, and combine forecasted fuel dryness level, ignition triggers (from lightning and recreation), critical burn environment conditions (windy, unstable, hot and dry), and resource availability (Table 1). Each day's forecast consists of one and only one of the nine categorical values. Forecasting methodologies vary across GCAs and across PSAs within a GCA, based on the expert opinion of the meteorologist and statistical correlations of weather and fuel dryness variables with large fire activity. Forecast categories 1-3 are based on fuel dryness alone, and indicate increasing fuel dryness. Categories 4-9 indicate "high risk" days on which the meteorologist predicts a greater than $20 \%$ chance of significant fire activity. High risk days can be caused by an elevated chance of ignitions, from either lightning (category 4) or recreation (category 8), a forecast value which is issued primarily on the $4^{\text {th }}$ of July when fireworks are commonly set off during celebrations. Weather factors may also cause the meteorologist to issue a high risk forecast, due to wind (category 5), unstable atmosphere and associated possible thunderstorm development (category 6), hot and dry weather (category 7), or dry weather (category 9).

When the forecast takes on a high risk value, regional staff often consults with the meteorologist in order to decide whether to preposition firefighting resources within the GCA. At high national preparedness levels, when firefighting resources are in high demand across the country, staff at the National Interagency Coordination Center in Boise, Idaho, use the 7-Day Fire Potential Outlook as an input into resource allocation decisions, along with existing fire activity and risks, socio-political considerations, and forecasted weather.

In this manuscript, we present preliminary analysis of the 7-Day Fire Potential Outlook, assessing the forecast's ability to predict ignitions and escaped fires in the Northwest and Southwest GCAs during the years 2009-2011. 
Table 1. 7-Day Significant Fire Potential Outlook forecast values. Each day's forecast corresponds to one and only one of these values.

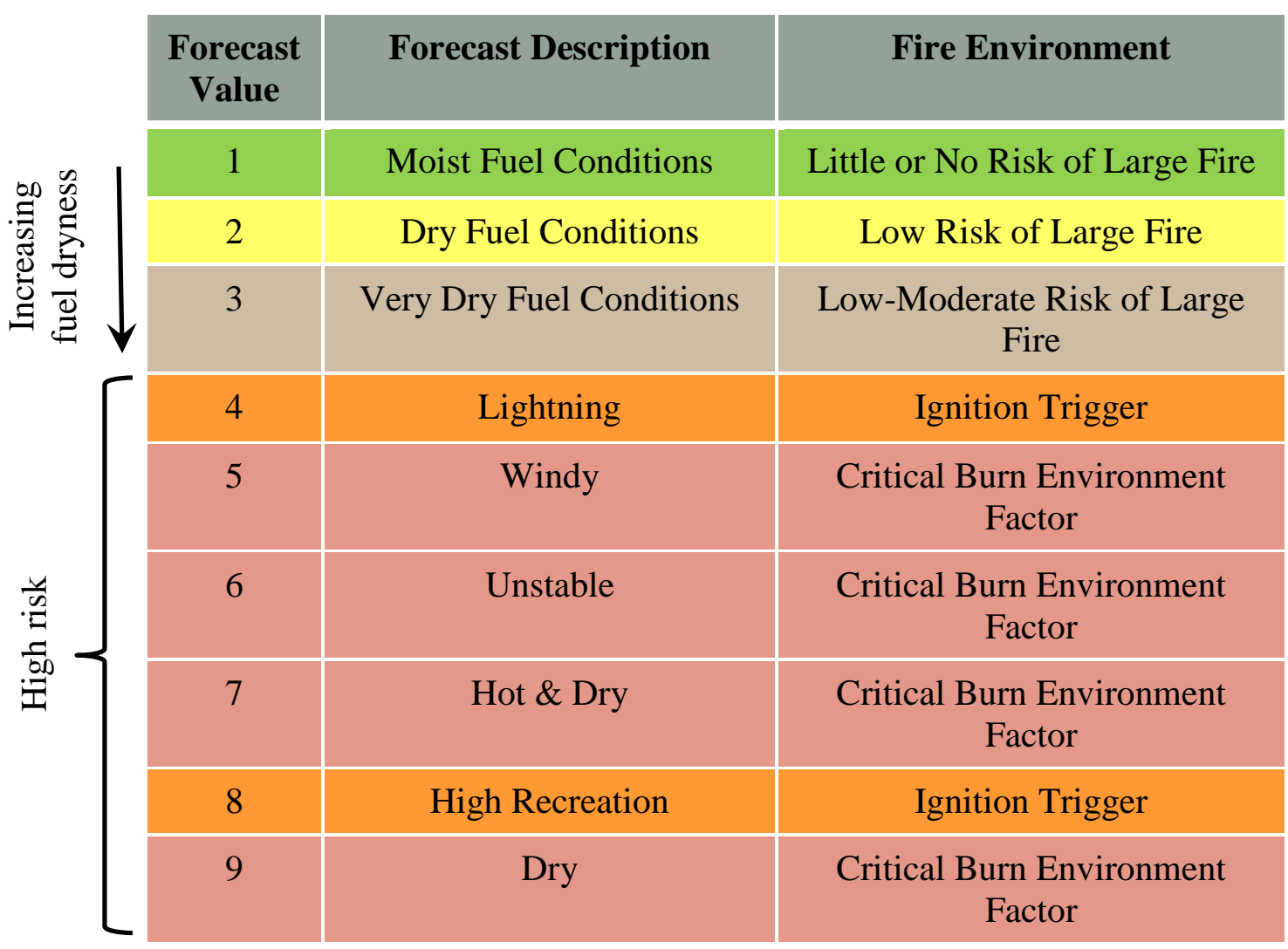

\section{Methods}

To assess the skill of the 7-Day Outlook, we obtained archived daily forecast values for PSAs in the Northwest (NWA) and Southwest (SWA) geographic coordination areas. Preliminary analyses were spatially constrained to these two geographic areas, and temporally constrained to 2009-2011, in order to refine our methods prior to initiating a nationwide analysis. While each day the forecast is issued for the current day and following six days, our initial analysis concentrates on the forecast values issued the for the current day (referred to as the Day 1 forecast) and Day 7 forecast.

To compare historical predicted fire occurrence (via the 7-Day Outlook) with actual historical fire occurrence, we utilized the national all-lands wildfire occurrence database (Short 2013, 2014). Fire ignition locations from the fire occurrence database (FOD) were intersected with annual PSA boundaries in ArcGIS 10.1. We utilized final fire size from the FOD to assess whether a fire escaped initial attack containment efforts; for our initial analysis, an escaped fire was defined as any incident with a final fire size greater than or equal to 121.3 hectares (300 acres).

Boxplots were used to assess the total number of ignitions by forecast level, as well as the total number of escaped fires by forecast level. We calculated $95 \%$ thresholds for number of ignitions and number of escaped fires, in order to establish confidence levels. Skill of the forecast was assessed in more detail within the NWA, where we used the log likelihood ratio to test whether the distribution of fire activity given the forecast was different from what would be expected randomly. The $\mathrm{R}$ statistical package was used to perform a G-test of independence with William's correction, and p-values were reported as a test of significance.

- Null hypothesis: fire activity occurs randomly with respect to forecast (therefore, the differences observed in the parallel boxplots are not statistically significant) 
- Alternative hypothesis: fire activity is significantly different than random with respect to the forecast (the differences observed in the parallel boxplots are statistically significant)

In this work we conclude that a forecast has skill if the null hypothesis is rejected (in other words, fire activity is significantly different than random with respect to the forecast), and the boxplots show a positive pattern in numbers of ignition or escapes with increasing forecast risk level.

In addition, we fitted a generalized additive Poisson regression model with spline functions to describe the potentially non-linear relationships that might exist between expected number of escapes and the three explanatory variables, number of ignitions, the day of the year, and the next-day forecast value (note that the next-day forecast value is used since a fire ignited on one day is not likely to escape containment efforts until the next day). The estimated effects of each of the explanatory variables were then graphed to illustrate the additive increase or decrease from average (with 0 on the y axis corresponding to average) due to the particular explanatory variable.

\section{Results}

The most frequently issued forecast value was 1 (moist), followed by 2 (dry), and 3 (very dry). Since increasing fuel dryness is meant to convey a heightened awareness of significant fire potential, it seems appropriate for the very dry fuel category to appear less often than the moist category (Table 2). Similarly, "high risk" forecast values (category 4-9) were issued much less frequently than fuel dryness forecasts (category 1-3), which again seems appropriate since they are meant to convey elevated risk of significant fire activity to resource managers. The NWA currently uses empirical regression equations between the predicted amount of lightning, fuel dryness, and predicted number of fire starts to decide when to issue a forecast of 4 (lightning ignition trigger). They use the other high risk forecast values more rarely, since the required $20 \%$ probability of a large fire threshold is seldom attained for any weather condition other than a lightning event. The recreation ignition (category 8) trigger was issued only four times during the period of analysis, and the dry forecast (category 9) was not issued at all during the period of analysis in these two GCAs.

Table 2. Number of times each forecast level was issued for Day 1 (current day) forecasts, between 2009 and 2011 , in the Southwest and Northwest Geographic Coordinating Areas (GCAs).

\begin{tabular}{|c|c|c|c|c|c|c|c|c|}
\hline $\begin{array}{c}\text { Forecast } \\
\text { Level }\end{array}$ & $\mathbf{1}$ & $\mathbf{2}$ & $\mathbf{3}$ & $\mathbf{4}$ & $\mathbf{5}$ & $\mathbf{6}$ & $\mathbf{7}$ & $\mathbf{8}$ \\
\hline NW & 3133 & 1150 & 202 & 60 & 16 & 58 & 0 & 2 \\
\hline SW & 5672 & 3456 & 2035 & 79 & 544 & 3 & 75 & 2 \\
\hline Total & 8805 & 4606 & 2237 & 139 & 560 & 61 & 75 & 4 \\
\hline
\end{tabular}

Patterns demonstrating the skill of the 7-Day Outlook in forecasting ignitions and escaped fires are evident in boxplots appearing in Figures 3 and 4. The number of ignitions per PSA is lower at dryness level 1 (moist) than at dryness levels 2 (dry) and 3 (very dry), which have roughly the same distribution of number of ignitions. Since the distribution of number of ignitions was similar during forecast levels 2 and 3, it seems the forecast does not exhibit skill in discerning the number of ignitions during dry versus very dry conditions. This result is perhaps not surprising, since the dryness levels were calibrated to the probability of large fires, not total ignitions. 

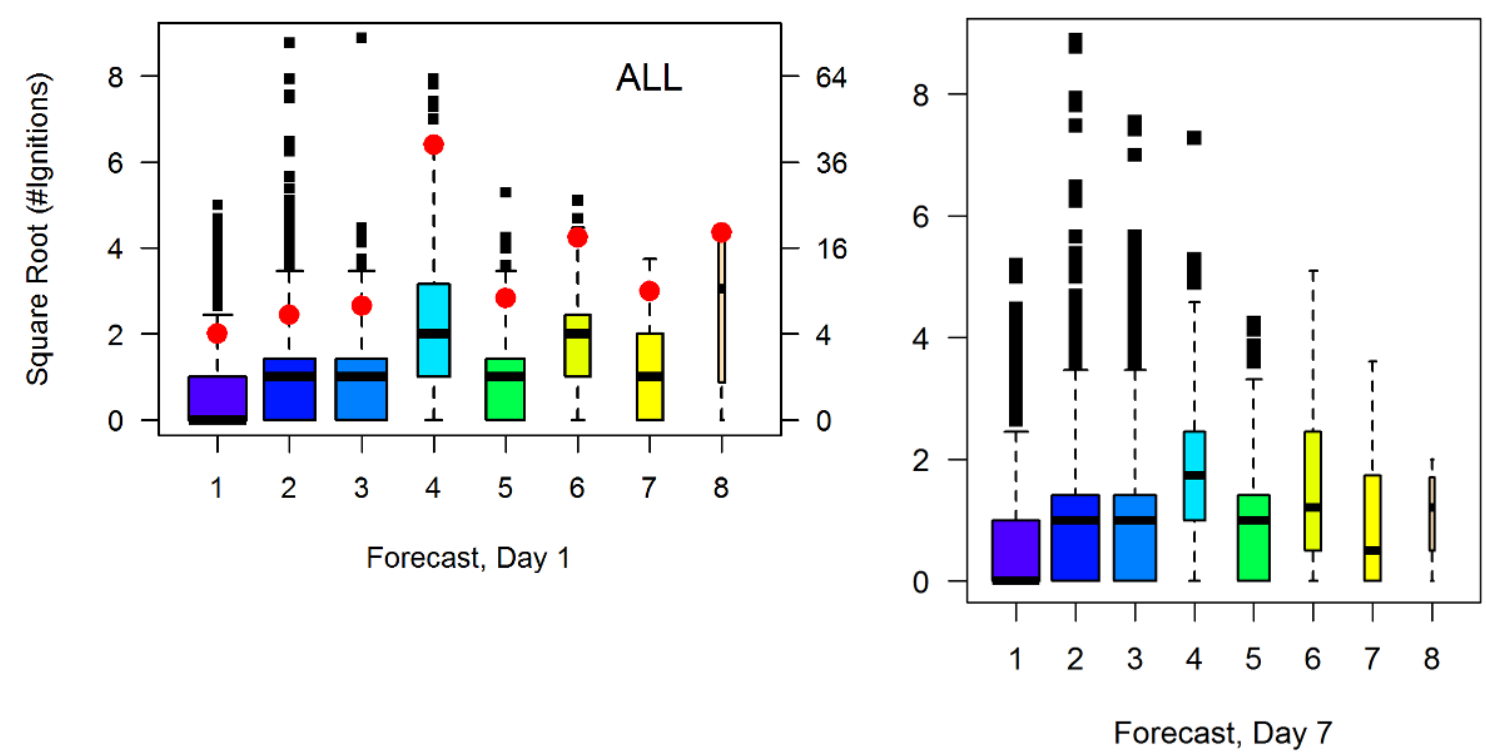

Figure 3. Distributions of number of ignitions (boxplots) in the Northwest and Southwest GCAs by forecast value, for forecast for current day (left panel) and seven days prior (right panel). Note that the y-axis represents the square root of the number of ignitions. The width of each boxplot is proportional to the square root of the number of times that value was forecasted (Table 2). Red dots in left panel indicate the $95^{\text {th }}$ percentile of the distribution.

On average, a higher number of historical ignitions occurred coincident with ignition trigger and critical burn environment forecast values (4 through 8) than for dryness level 1 (moist), indicating some skill in predicting ignitions in these high risk forecast levels as well. In the same-day forecast, on average, the highest numbers of ignitions occurred under forecast level 8 (high recreation), followed by level 6 (unstable), and level 4 (lightning), with the ignition numbers being higher than those for dryness levels 2 and 3 on average. Evidently, days that the meteorologists forecast lightning do indeed experience higher lightning levels, judging by higher ignitions on those days. The level 6 forecast indicates unstable atmospheric conditions, which are often associated with thunderstorm development and lightning, and thus elevated numbers of ignitions. The level 5 forecast (windy day) had a similar distribution of number of ignitions as dryness levels 2 and 3, which is not surprising since wind would be expected to promote fire growth but not ignitions. The patterns in the boxplots are similar for the forecast values seven days ahead, suggesting that the forecast may be used up to a week ahead to indicate days with heightened levels of ignitions.

Boxplots give the $25^{\text {th }}, 50^{\text {th }}$, and $75^{\text {th }}$ percentiles of the distribution in addition to outliers. Ninety-fifth percentiles may also be a useful tool for managers. These were calculated for the number of ignitions and escaped fires by forecast value and added to the boxplots (Figures 3 and 4). For example, historically, fewer than four ignitions per PSA were observed on 95 percent of days forecasted as moist (level 1) conditions (Figure 3). The $95^{\text {th }}$ percentile for ignitions is highest for days with lightning forecasts (level 4), at approximately 40 ignitions.

As noted above, the forecast was designed to predict significant fire activity rather than ignitions, although of course ignitions are a prerequisite to significant fire activity. Thus, we also assessed the performance of the forecast with regard to escaped fires (Figure 4). Because escaped fires are rare, the median $\left(50^{\text {th }}\right.$ percentile $)$ number of escaped fires on any given day per PSA is zero across all forecast values. However, the $95^{\text {th }}$ percentile is one escaped fire during same-day forecasts of 3 (very dry), 4 (lightning), 5 (windy), and 7 (hot and dry), indicating that there is a 5\% chance of having at least one escaped fire during days with these forecasts. Conversely, managers may expect no escapes on 95 percent of the days when the forecast is 1 (moist), 2 (dry), 6 (unstable), or 8 (recreation). In other words, there is less than a 5 percent chance of having at least one escape. Specifically, during days 
with forecast level 4, the estimated probability of at least one escape was 0.22 for the same-day forecast in the NW, with $95 \%$ confidence limit between $0.13-0.31$, and 0.14 in the $\mathrm{SW}$, with $95 \%$ confidence limit between $0.05-0.23$. Because a forecast level 4 is issued to indicate a $20 \%$ or greater risk of a significant fire event, this result indicates good skill of the category 4 forecast in that the $20 \%$ probability fell within the confidence interval of the observed proportion of escapes in both GCAs. However, the Day 7 forecasts for level 4 had less skill in predicting the probability of at least one escape, with estimated probability of $7.5 \%(1.4-15 \%)$, which was significantly different than the expected $20 \%$ or greater risk. Thus, the forecast seven days in advance does not have as much skill in predicting escaped fires as the same-day forecast. The number of cases in forecast level 8 is too small to make any conclusions about the skill of the forecast for escapes for this level. The pattern is quite similar in both the Day 1 (same day) and Day 7 forecasts, indicating that the 7-Day Outlook forecast might be useful in indicating PSAs where firefighting resources might be prepositioned up to seven days ahead in order to prevent escaped fires. It should be noted that we used a threshold of 121.4 hectares (300 acres) across all PSAs to indicate an escaped fire, while each PSA has a different threshold for determining the size of a "Significant Fire", varying from 20.2 to 4046.9 hectares (50 to 10,000 acres), so there is some discrepancy in the definitions used to define an escaped versus significant fire.
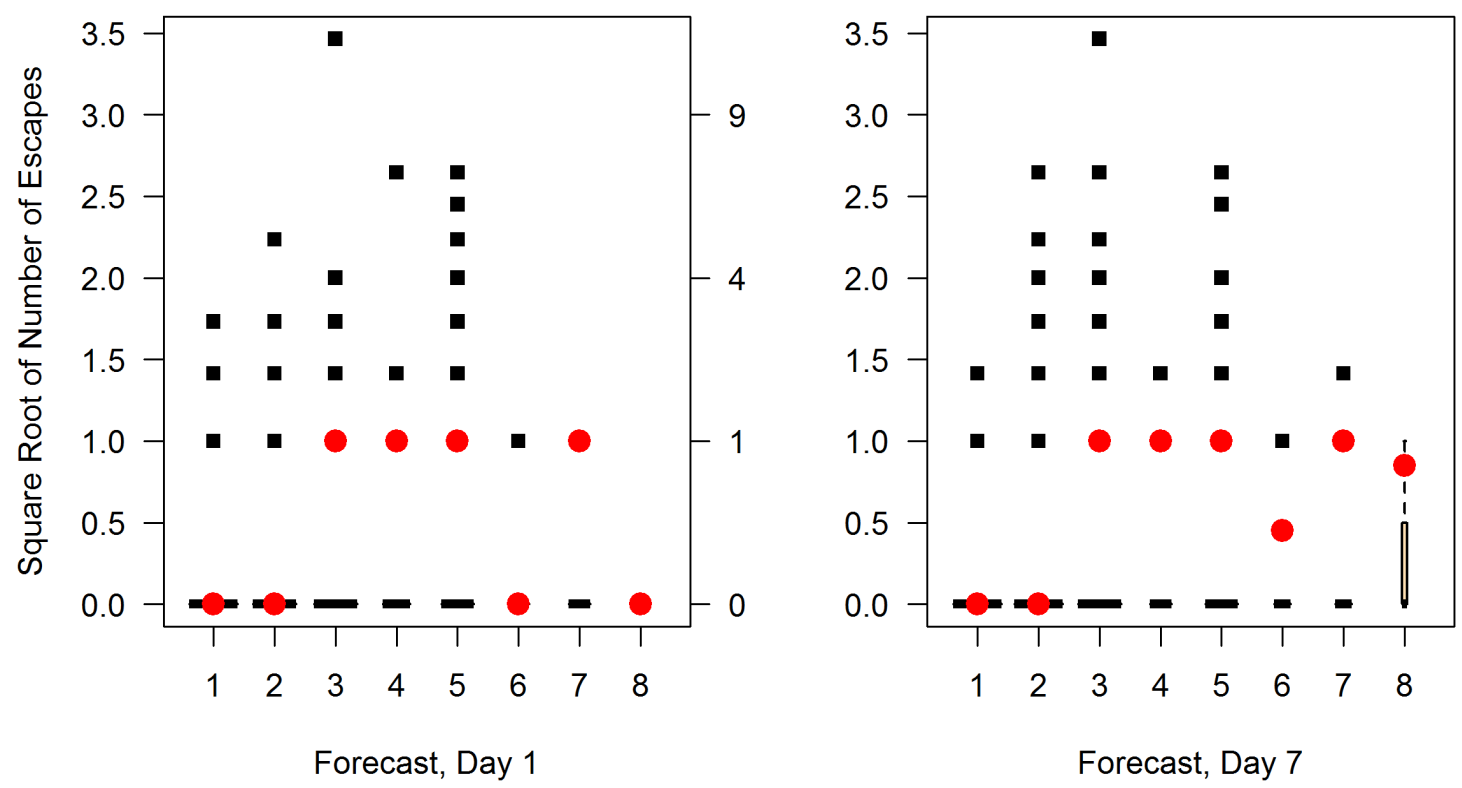

Figure 4. Distributions of number of escaped fires (final fire size $>=121.4$ hectares (300 acres)) using the same day forecast (left panel) and forecast value from seven days ahead (right panel) in the Northwest and Southwest GCA by forecast value. The red dot signifies the $95^{\text {th }}$ percentile of the distribution. Escaped fires were lagged one day, assuming that a fire ignited on one day will not usually escape initial attack and grow to 121.4 hectares (300 acres) until the next day.

The statistical significance of the differences seen in the boxplots was tested using the log likelihood ratio. In the GCA as a whole (totals for all PSAs), fire activity with respect to the forecast occurred differently from random, indicating the forecast has skill at predicting ignitions and escaped fires at the GCA level ( $\mathrm{p}<=1.06 \mathrm{e}-14)$. The log likelihood ratio tests, which were also performed for the Day 1 forecasts in each PSA in the NWA, indicate skill of the 7-Day Outlook in predicting ignitions in 11 of 12 PSAs and escaped fires in only 5 of 12 PSAs. Escaped fires are likely more challenging to predict than ignitions for several reasons, including their rarity. In fact, the log likelihood ratio test may not have had an adequate number of escaped fires in some PSAs, and may have failed to indicate statistical significance due to the low sample size. 
Although the skill of the forecasts look good probabilistically, in absolute numbers there may be many days where the forecast missed predicting high fire risk. For example, although the chance of at least one escape was very small (approximately 2 percent) on days with forecast prediction level 1 (moist) or 2 (dry), indicating low risk of significant fires, the actual number of days that had at least one escape in these forecast levels and over the three years of the study was 318. Seven of those 318 days had more than three escapes. Up to 10 escaped fires occurred within a PSA on days when the forecast was not being issued; sometimes these days were during winter months that may not have been considered part of the core fire season, but other times these days occurred during the summer months.

We analysed the number of escaped fires as a function of number of ignitions, day in year, and next day forecast level (grouped into two groups, the "high risk" forecast values of 4-7 and the dryness levels 1-3), using Poisson regression (Figure 5). The number of escapes increased with the number of ignitions in both the NWA and SWA. In the SWA, an increase in the number of escaped fires is seen up to about 10 ignitions, after which there is no further increase. In the NWA, we see a similar pattern up to about 50 ignitions, with perhaps another increase above 60 ignitions, although the standard errors are large. The seasonal patterns in the SWA and NWA are different, with the SWA showing more escapes on average around 100-150 days into the year (mid-April through late May), corresponding with spring dryness before the arrival of monsoon rains, while the NWA shows more escapes around 210-250 days into the year (early August through mid-September), corresponding with dry fuels at the end of the summer season and possibly convective thunderstorm development. In the SWA, the high risk forecast days (categories 4-7) show an estimated 2.35 times more escaped fires per ignition than days with a dryness level forecast (categories 1-3), with a 95\% confidence interval of $1.9-2.87$. In the NWA, a similar pattern is evident, with about four times more escaped fires per ignition on high risk forecast days $(95 \%$ confidence interval $2.5-6.4)$.
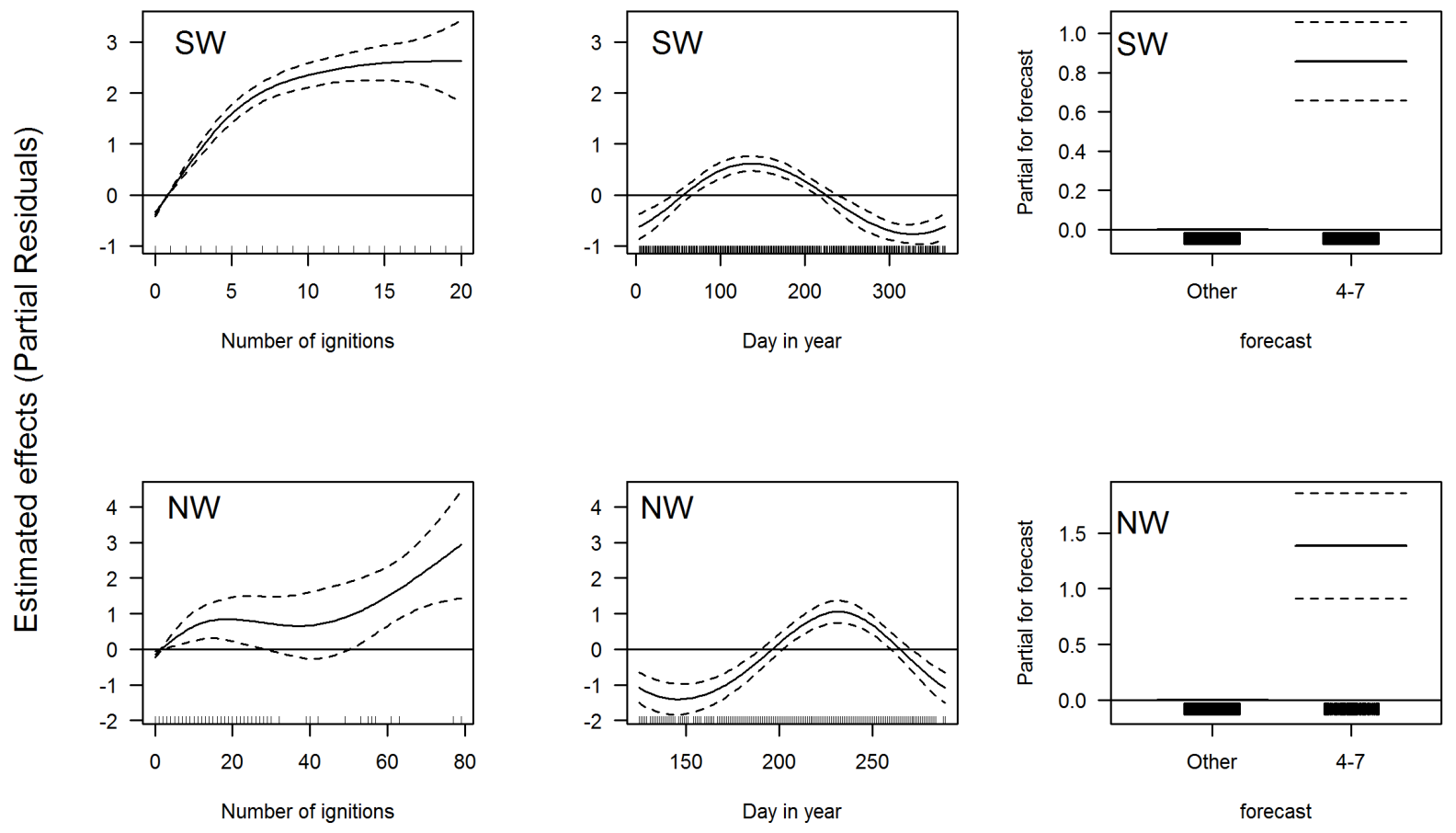

Figure 5. Partial residuals from Poisson regression demonstrating estimated effects of number of ignitions, day in year, and 7-Day Outlook forecast on number of escaped fires in the Northwest (NW) and Southwest (SW) Geographic Coordinating Areas. The partial residual plots show the additive increase or decrease from average (with 0 on the $y$ axis corresponding to average) due to the particular explanatory variable. The y axis is in units of the natural log. 


\section{Discussion and Conclusions}

Generally speaking, the 7-Day Fire Potential Outlook demonstrated better than random prediction of wildfire activity in the NWA. In the NWA and SWA, numbers of ignitions were lower at dryness level 1 (moist) than at dryness levels 2 (dry) and 3 (very dry) and on days with forecasts indicating lightning, unstable conditions, high recreation, windy conditions, or hot and dry conditions. Escaped fires were more likely under forecast levels 3 (very dry), 4 (lightning), 5 (windy), and 7 (hot and dry) than forecasts 1 (moist) and 2 (dry), with forecasts 6 (unstable) and 8 (high recreation) showing predictive skill seven days ahead but not during the same-day forecasts. In general, the forecasts showed skill in identifying days with elevated numbers of ignitions and potential for escaped fires not only for the current day's forecast, but also for forecasts made a week before, indicating the forecast might be useful in prepositioning of fire suppression resources nationally up to seven days in advance. In spite of this demonstrated skill, the forecasts missed many days with escaped fires.

The relationship between fuel dryness and fire ignitions is well established in the literature (Andrews et al. 2003), and thus the increasing number of ignitions across dryness levels 1 to 3 makes sense, but the weather conditions leading to significant fire activity are less well understood, adding to challenges in predicting fire activity and escapes. The rarity of escaped fires alone makes their prediction challenging. Adding to the difficulty in forecasting rare events, gridded weather model output also contains uncertainties and imperfections, which are then passed to the fire models. Wind speeds and directions tend to vary considerably within PSAs, causing spatial variation in the potential for fires to grow large. Additionally, if regional and national decision makers utilize a skilled forecast to effectively preposition suppression resources, which then successfully contain a fire while it is small, the performance of the forecast could appear poor in some cases, since it would appear that significant fires did not occur on days with high risk forecasts, when in fact the forecast itself contributed to containment during initial attack.

We found that the number of escaped fires increased with the number of ignitions in both the SWA and NWA, with the number of escaped fires per ignition being higher in the SWA than in the NWA. Different seasonal trends in escaped fires are present in the SWA and the NWA, with the most common period for escaped fires coming earlier in the year in the SWA (mid-April through late May, corresponding with spring dryness before the arrival of monsoon rains) than in the NWA (early August through mid-September, corresponding with dry fuels at the end of the summer season and possibly convective thunderstorm development). These findings illustrate the different fire regimes and response capabilities of fire suppression resources in these two GCAs. Forecasted high risk days (categories 4-7) had about twice as many escaped fires per ignition in the SWA and about four times more escaped fires per ignition in the NWA. On days with high risk forecasts, prepositioning of fire suppression resources or implementation of fire prevention measures might bring down the number of escaped fires, where desired in order to meet land management objectives.

In this initial work, we focused only on the three years 2009, 2010, and 2011, and on two of the ten geographic areas in the conterminous US. We are currently in the process of expanding the analysis to include a total of six years of reliable historical forecast data (2007 to 2012). Expanding the dataset will help to address the statistical issues with small sample sizes of escaped fires. We will also incorporate analysis of additional GCAs, in order to begin to be able to address national-level resource allocation issues. In addition, we will examine geographical and fuels characteristics as well as longer term fire history data to determine if additional non-weather-related variables (e.g. fuel type, land ownership) may improve the skill of the forecasts, in particular, by decreasing the number of days when escaped fires occurred but were not predicted. 


\section{References}

Andrews, PL, Loftsgaarden, DO, Bradshaw, LS (2003) Evaluation of fire danger rating indexes using logistic regression and percentile analysis. International Journal of Wildland Fire 12, 213-226.

Short, KC (2013) 'Spatial wildfire occurrence data for the United States, 1992-2011 [FPA_FOD_20130422].' (RMRS USDA Forest Service: Fort Collins, CO). Available at http://dx.doi.org/10.2737/RDS-2013-0009

Short, KC (2014) A spatial database of wildfires in the United States. Earth System Science Data 6, 127. 